\title{
1 Efficient Alcoholic Conversion of Glycerol by Engineered Saccharomyces cerevisiae
}

2 Sadat M. R. Khattab ${ }^{\mathrm{a}, \mathrm{b} \#}$, Takashi Watanabe ${ }^{\mathrm{a} \#}$

$3 \quad{ }^{\mathrm{a}}$ Research Institute for Sustainable Humanosphere, Kyoto University, Japan

$4 \quad{ }^{\mathrm{b}}$ Faculty of Science, Al-Azhar University, Assiut, Egypt

$5 \quad$ Running title

6 Alcoholic Conversion of Glycerol by Engineered Yeast

7 \#Address correspondence to: Sadat M.R. Khattab, khattab.sadatmohamedrezk.7c@kyoto-u.ac.jp;

$8 \quad$ Takashi Watanabe, twatanab@rish.kyoto-u.ac.jp

9 KEYWORDS: Saccharomyces cerevisiae, bioethanol, glycerol conversion, metabolic

10 engineering, cofactors 


\section{ABSTRACT}

Glycerol is an eco-friendly solvent that enhances plant biomass decomposition via glycerolysis in many pretreatment methods. Nonetheless, the lack of efficient conversion of glycerol by natural Saccharomyces cerevisiae hinders its use in these methods. Here, we have aimed to develop a complete strategy for the generation of efficient glycerol-converting yeast by modifying the oxidation of cytosolic nicotinamide adenine dinucleotide (NADH) by an $\mathrm{O}_{2}$ dependent dynamic shuttle, while abolishing both glycerol phosphorylation and biosynthesis. By following a vigorous glycerol oxidation pathway, the engineered strain increased the conversion efficiency (CE) to up to $0.49 \mathrm{~g}$ ethanol/g glycerol (98\% of theoretical CE), with production rate > $1 \mathrm{~g} \cdot \mathrm{L} \cdot \mathrm{h}$, when glycerol was supplemented in a single fed-batch fermentation in a rich medium. Furthermore, the engineered strain fermented a mixture of glycerol and glucose, producing $>86$ $\mathrm{g} / \mathrm{L}$ bioethanol with $92.8 \%$ CE. To our knowledge, this is the highest ever reported titer in this field. Notably, this strategy changed conventional yeast from a non-grower on minimal medium containing glycerol to a fermenting strain with productivity of $0.25-0.5 \mathrm{~g} \cdot \mathrm{L} \cdot \mathrm{h}$ and $84-78 \% \mathrm{CE}$, which converted $90 \%$ of the substrate to products. Our findings may improve the utilization of glycerol in several eco-friendly biorefinery approaches.

\section{IMPORTANCE}

With the development of efficient lignocellulosic biorefineries, glycerol has attracted attention as an eco-friendly biomass-derived solvent that can enhance the dissociation of lignin and cell wall polysaccharides during the pretreatment process. Co-conversion of glycerol with the sugars

31 released from biomass after glycerolysis increases the resources for ethanol production and lowers the burden of component separation. However, titer productivity hinders the industrial 
33 application of this process. Therefore, generation of efficient glycerol-fermenting yeast will

34 promote the applicability of integrated biorefineries. Furthermore, glycerol is an important

35 carbon source for the production of various chemicals. Hence, control of the metabolic flux of

36 yeast grown on glycerol will contribute to the generation of cell factories that produce chemicals

37 such as ethanol from glycerol, which will boost biodiesel and bioethanol industries. Additionally,

38 the use of glycerol-fermenting yeast will reduce global warming and generation of agricultural

39 waste, leading to the establishment of a sustainable society. 
The demand for ethanol has increased remarkably because of its use in sanitizers in the COVID19 pandemic, necessitating enhancement in its production via various pathways, including glycerol fermentation. In the past decade, glycerol $\left(\mathrm{C}_{3} \mathrm{H}_{8} \mathrm{O}_{3}\right)$-producing industries, particularly the biodiesel industry, have produced substantial amounts of glycerol (1). However, glycerol is reduced more than other fermentable sugars (2). In addition, glycerol as a carbon source is poorly utilized, primarily via the glycerol-3-phosphate pathway (hereafter referred to as the G3P pathway), which is composed of glycerol kinase (GUT1) and flavin adenine dinucleotide (FAD)dependent mitochondrial glycerol-3-phosphate dehydrogenase (GUT2) (3). Yeast prefers biosynthesizing glycerol, as it mitigates osmotic stress and optimizes redox balance (4). In contrast, glycerol catabolism is subject to repression and transcriptional regulation of glucose metabolism via several respiratory factors, as well as GUT1 and GUT2 (5-7).

Several groups have attempted to ferment glycerol by overexpressing the native oxidative pathway (DHA; dihydroxyacetone pathway) in S. cerevisiae. Overexpression of the endogenous glycerol dehydrogenase ( $S c G C Y 1)$ with dihydroxyacetone kinase $(S c D A K 1)$ led to the production of $0.12 \mathrm{~g}$ ethanol/g glycerol $\left(\mathrm{g}^{\mathrm{e}} / \mathrm{g}^{\mathrm{g}}\right)$, and the production rate was $0.025 \mathrm{~g} \cdot \mathrm{L} \cdot \mathrm{h}(8)$. The importance of glycerol as a carbon source that can be utilized by yeast cells prompted a study on $52 S$. cerevisiae strains, which revealed the intraspecies diversity of yeast, ranging from good glycerol growers to non-growers. The growth phenotype is controlled by quantitative traits (9). Reports showed that many genes such as $U B R 2$, encoding a cytoplasmic ubiquitin-protein ligase E3, link GUT1 with growth on glycerol in synthetic medium in the absence of supplements (10). In contrast, heterologous replacement of G3P with DHA, combined with the use of the glycerol facilitator FPS1, resulted in the restoration of growth characteristics similar to those of the parental strain or even higher (11). This replacement in a glycerol grower ancestor by limiting 
the oxygen in shaking flask cultures increased ethanol production from 0.165 to $0.344 \mathrm{~g}^{\mathrm{e}} / \mathrm{g}^{\mathrm{g}}$ in buffered synthetic medium. The maximum titer produced reached $15.7 \mathrm{~g} / \mathrm{L}$ after $144 \mathrm{~h}(12)$. Until now, glycerol has been reported as a non-fermentable carbon source for Saccharomyces cerevisiae, and attempts have been made to ferment it using this yeast (13). Furthermore, the methylotrophic yeast Ogataea polymorpha has been modified for bioethanol production from glycerol by overexpressing multiple genes involved in either the DHA or G3P pathways. In addition, FPS1, pyruvate decarboxylase $(P D C)$, and alcohol dehydrogenase $(A D H) 1$ were overexpressed. Nonetheless, the overall titer produced was $10.7 \mathrm{~g} / \mathrm{L}$ ethanol with a conversion efficiency $0.132 \mathrm{~g}^{\mathrm{e}} / \mathrm{g}^{\mathrm{g}}(14)$. However, reports on known native or genetically engineered $S$. cerevisiae strains that ferment or convert glycerol efficiently to ethanol are lacking.

We have previously reported microwave-assisted pretreatments of recalcitrant lignocellulosic biomass in aqueous glycerol (15), which was further improved with the catalysis of alum $\left[\mathrm{AlK}\left(\mathrm{SO}_{4}\right)_{2}\right]$ (16). Fractionation of sugars from glycerol is expensive. Therefore, $S$. cerevisiae capable of efficiently fermenting glycerol with glucose after glycerolysis pretreatment of biomass should be developed. Therefore, in this study, we have aimed to model the $S$. cerevisiae to redirect glycerol traffic to bioethanol production in the presence of glucose via systematic metabolic engineering outlined in Fig. 1. Modeling the conversion of glycerol and sugars after lignocellulosic biomass glycerolysis will synergize ethanol production, which is necessary for cost-effective distillation processes with fewer purification steps. Thence, many biorefineries are promoted, as well as the merger of the bioethanol and biodiesel industries. ["(Figure 1)"]

\section{RESULTS AND DISCUSSION}




\section{Growth of the original strain on glycerol as the sole carbon source. $S$. cerevisiae cannot} ferment glycerol. In addition, some strains of $S$. cerevisiae cannot grow in culture media containing glycerol as the sole carbon source in the absence of supplements. Swinnen et al. classified the S288C strain as a negative glycerol grower on synthetic medium without supporting supplements (9). S. cerevisiae D452-2 (Table 1), which was used in this study, is an ancestor of S288C (17-19) (Fig. S1). The strain could not use glycerol as the sole carbon source in yeast nitrogen base (YNB) medium supplemented with $20 \mathrm{mg} / \mathrm{L}$ leucine and histidine, and 5 $\mathrm{mg} / \mathrm{L}$ uracil or even when $10 \times$ supplementation was used. The maximum $\mathrm{OD}_{600}$ after $120 \mathrm{~h}$ was only 0.28 (Fig. S2). Hence, in this study, we used a conventional yeast peptone (YP) medium to avoid these limitations.

Enhancement of glycerol flux via glycerol dehydrogenase. To overcome the limitations of glycerol flux in $S$. cerevisiae, $O p G D H$ from the methylotrophic yeast $O$. polymorpha, encoding glycerol dehydrogenase (20), was heterologously overexpressed in the URA3 locus of D452-2 under the control of an efficient expression system (21) consisting of the glyceraldehyde 3phosphate dehydrogenase promoter $(T D H 3)$ and mutated DITyrosine terminator $\left(D I T 1_{d 22}\right)$. In contrast to the native strain, which did not show any enzyme activity, $3.5 \mathrm{mU} / \mathrm{mg}$ GDH activity was observed for the transformant harboring $O p G D H$ (Table 2). Compared to $167 \mathrm{mM}$ potassium phosphate ( $\mathrm{pH}$ 7.5), HEPES buffer increased glycerol dehydrogenase activity by 3.75fold, which is similar to that reported previously (22). Consequently, compared to that of the reference strain, glycerol consumption increased from $8 \%$ to $58 \%$. Concomitantly, the production of ethanol increased by 2.64 -fold, from $4.47 \mathrm{~g} / \mathrm{L}$ (in the reference strain) to $11.82 \mathrm{~g} / \mathrm{L}$, reaching productivity of $0.27 \mathrm{~g}^{\mathrm{e}} / \mathrm{g}^{\mathrm{s}}$ after $26 \mathrm{~h}$ (Fig. 2). Aßkamp et al. reported that external mitochondrial NADH dehydrogenase (Nde1) is involved in glycerol metabolism in the presence 
108 of oxygen as the final electron acceptor (23), although cytosolic NAD ${ }^{+}$was partially regenerated.

109 Under semi-aerobic conditions, the NADH/NAD ${ }^{+}$ratio increased by $45 \%$ (Table 2). Therefore,

110 overexpression of $O p G D H$ in $S$. cerevisiae is the first step in the alcoholic fermentation of

111 glycerol. Nonetheless, overexpression of only $O p G D H$ in GDH strain was not sufficient to

112 induce an efficient conversion (Fig. 2). In contrast, the conversion efficiency in strains

113 overexpressing endogenous glycerol dehydrogenase $S c G C Y 1$ alone or in combination with whole

114 DHA pathway was lower than that of strains overexpressing $O p G D H$ (data not shown). ["(Table

115 1)"]

116 Modification of NADH oxidation. NADH is produced during glucose metabolism, and

117 heterologous expression of NoxE in S. cerevisiae has been used to successfully decrease excess

118 NADH production during fermentation of glucose, with increase in ethanol, 2,3-butanediol or

119 acetoin production (24-28). We substituted glycerol-3-phosphate dehydrogenase (GPD) shuttles

120 with LINoxE and observed that this replacement abolished glycerol biosynthesis by $98 \%$, with

121 increase in ethanol production by $9 \%$ during fermentation of $10 \%$ glucose (data not shown).

122 Replacement of ScGPDI by LINoxE in the GDH strain overcame the deficiency of NADH

123 oxidation by the natural cytosolic shuttles and induced efficient regeneration of $\mathrm{NAD}^{+}$for

124 glycerol oxidation. In addition, $S c G P D 1$ replacement reduced circulation of DHAP into glycerol

125 biosynthesis or/and G3P — glycerolipid pathway. Subsequently, this promoted continuous

126 conversion of glycerol to ethanol. Substantial improvement in ethanol production was observed

127 using this combination in the GN strain (Table 1), which harbouring OpGDH and LlNoxE, with

128 production being $28 \%$ of that of the GDH strain. The ethanol titer increased from 11.82 to 13.27

$129 \mathrm{~g} / \mathrm{L}\left(0.31 \mathrm{~g}^{\mathrm{e}} / \mathrm{g}\right.$ substrate consumed $)$ after $26 \mathrm{~h}$, and then to $14.42 \mathrm{~g} / \mathrm{L}$ with further extension of the

130 fermentation time to $32 \mathrm{~h}$ (Fig. 2b). Surprisingly, the enzyme activity of glycerol dehydrogenase 
131 increased by $51 \%$, whereas that of TPI1 decreased by $65 \%$. The reasons underlying these

132 changes remain unclear. The effectiveness of oxidation was further evident from the restoration

133 of the NADH/NAD ${ }^{+}$ratio (Table 2). $\mathrm{NAD}^{+}$level was restored during glycerol conversion by

134 integrating LINoxE in the GDH strain; nevertheless, it was not sufficient for efficient ethanolic

135 conversion. ["(Table 2)"]

136 Complete overexpression of the DHA pathway Considering the efficiency of glycerol

137 conversion to ethanol by the GN strain, the activities of other genes in the DHA pathway,

138 namely, ScTPI1, ScDAKs, and CUFPS1, may still be limited, which may affect the traffic of

139 glycerol to ethanol. The DHA pathway is unusual, as DHAP is distributed in phospholipid and

140 methylglyoxal biosynthesis pathways $(29,30)$. Therefore, further reduction of the bifurcation of

141 DHAP can be overcome by overexpressing ScTPI1. There has been no report of ScTPII

142 overexpression aiming to enhance ethanolic fermentation, although the pivotal role of ScTPII is

143 evident from another study on glycerol production (31). Furthermore, dihydroxyacetone may

144 accumulate inside cells expressing $O p G D H$ and reduce transport of DHA, and its toxific effects

145 (32) could be the driving force for alcohol production. ScDAK1 and CuFPS1 support the

146 fermentation of glycerol to ethanol $(8,12,14)$. In this study, we further supported the activities

147 of ScTPI1 and ScDAK2 (with considerably lower $K m_{\text {(DHA- ATP) }}$ ) with ScDAK1 and CuFPS1. After

148 integrating this set of genes in the GN strain, the GN-FDT strain unequivocally overcame the

149 obstacle of ethanol re-consumption before the complete utilization of glycerol. The consumption

150 rate reached $1 \mathrm{~g} \cdot \mathrm{L} \cdot \mathrm{h}$, with increase in ethanol titer to $21 \mathrm{~g} / \mathrm{L}$, which represents $145 \%$ and $469 \%$ of

151 the titers of the GN and native strains, respectively. Nonetheless, the conversion efficiency was

152 less than $48 \%$ of the theoretical value (Fig. 2). Compared to that of the native reference strain,

153 dihydroxyacetone kinase activity in GN-FDT improved by $185 \%$, while compared to that of the 
154 GN strain, glycerol dehydrogenase and ScTPI1 were activated by $9 \%$ and $6 \%$, respectively

155 (Table 2). Hence, increasing the activities of ScDAK and ScTPII by supporting the influx of

156 glycerol by CuFPS1 represents another essential step for improving conversion of glycerol to

157 ethanol. "(Figure 2)"]

\section{Reinforcement of the DHA pathway while abolishing the native G3P route. Native $S$.} cerevisiae adapts to redox regulation via glycerol biosynthesis (4). Furthermore, the activity of $A D H$ within the cells grown on glycerol-yeast extract medium was ten times higher than that in cells cultured in glucose (33). In addition, the availability of ATP for ScDAKs may be limited by the presence of $S c G U T 1$ (11). Therefore, enhancement of the efficiency of glycerol conversion was expected by another copy of the DHA pathway concomitant with the replacement of ScGUT1. Accordingly, overexpressing another copy of CuFBS1, OpGDH, ScDAK1, and ScTPI1 through the M1 module (Fig. 3), which were placed under a highly constitutive expression system $(21,34,35)$, enhanced the activities of $S c D A K$ and $S c T P I 1$ by $256 \%$ and $316 \%$, respectively, compared to that in the GN-FDT strain. In addition, the efficiency of NADH oxidation increased with reduction in the NADH/NAD ${ }^{+}$ratio to 0.11 (Table 2). Interestingly, the GN-FDT-M1 (SK-FGG) strain showed outstanding conversions; the glycerol consumption rate reached $2.6 \mathrm{~g} \cdot \mathrm{L} \cdot \mathrm{h}$, and ethanol productivity was $1.38 \mathrm{~g} \cdot \mathrm{L} \cdot \mathrm{h}$ with conversion efficiency of 0.44 $\mathrm{g}^{\mathrm{e}} / \mathrm{g}^{\mathrm{s}}$ (Fig. 2). This suggests that the glycerol flux and efficiency of conversion are controlled by the extent to which the DHA pathway restores NAD ${ }^{+}$. "(Figure 3)"]

To further investigate the metabolic engineering in SK-FGG, alcoholic conversion of higher initial concentrations $(110 \mathrm{~g} / \mathrm{L})$ of glycerol in the presence or absence of $22.5 \mathrm{~g} / \mathrm{L}$ glucose (Table 3 [A and B]) was tested. Furthermore, fed-batch fermentation of approximately $100 \mathrm{~g} / \mathrm{L}$ 
glycerol was performed under condition [B] (Table $3[\mathrm{C}]$ ). To further confirm that the engineered strain did not substantially repressed by glucose metabolism (5-7), the glucose level was doubled to $45 \mathrm{~g} / \mathrm{L}$ with reduction in glycerol concentration by $25 \%$ to $82 \mathrm{~g} / \mathrm{L}$ before the fedbatch fermentation of glycerol (Table $3[\mathrm{D}]$ ). This scheme was also assessed for the ability to yield an economical distillable ethanol titer (Table $3[\mathrm{D}]$ ). The state $[\mathrm{D}]$ is similar to that obtained after the glycerolysis process (16). With case [A], the conversion efficiency reached $98 \%\left(0.49 \mathrm{~g}^{\mathrm{e}} / \mathrm{g}^{\mathrm{g}}\right)$ with production rate of $>1 \mathrm{~g} \cdot \mathrm{L} \cdot \mathrm{h}$ of ethanol after consumption of $82.5 \mathrm{~g} / \mathrm{L}$ glycerol under the fed-batch condition. In addition, $1.14 \mathrm{~g} / \mathrm{L}$ acetic acid was produced. Even in the presence of $22.55 \mathrm{~g} / \mathrm{L}$ glucose, the conversion efficiency of glycerol was almost unaltered (Table $3[\mathrm{~B}])$. Interestingly, the engineered strain was exceptional in its capacity of harmonizing the conversion of glycerol with glucose, along with an accumulation of $>86 \mathrm{~g} / \mathrm{L}$ bioethanol during an additional fed-batch of glycerol (Table 3 [D]). Compared to that in case [C], cell density increased by $31 \%$, along with a minor reduction in the efficiency of ethanol conversion in [D] (Table 3). ["(Table 3)"]

Ethanolic conversion of glycerol as the sole carbon source. To avoid the interference of nutrients in the complex YP medium, the conversion efficiency of SK-FGG was eventually determined using glycerol as the sole carbon source in YNB medium supplemented with $1 \times 20$ $\mathrm{mg} / \mathrm{L}$ leucine and histidine in a single batch. The conversion experiments were performed under four different conditions of oxygen availability, as mentioned in the Methods section. Significant growth or production of ethanol was not observed under strict anaerobic condition (Table 4). Under micro-aerobic condition, the strain consumed $37.17 \mathrm{~g}$ glycerol, with a consumption rate $0.62 \mathrm{~g} \cdot \mathrm{L} \cdot \mathrm{h}$ and production rate $0.25 \mathrm{~g} \cdot \mathrm{L} \cdot \mathrm{h}$. Acetic acid accumulated at $0.78 \mathrm{~g} / \mathrm{L}$ under this condition, and the efficiency of ethanol conversion approached $0.42 \mathrm{~g}^{\mathrm{e}} / \mathrm{g}^{\mathrm{g}}$ (Table 4). Glycerol is 
consumed more rapidly in a semi-aerobic atmosphere. The consumption rate was $>1 \mathrm{~g} \cdot \mathrm{L} \cdot \mathrm{h}$, which increased the ethanol production rate to $0.44 \mathrm{~g} \cdot \mathrm{L} \cdot \mathrm{h}$, resulting in the accumulation of 20.97 $\mathrm{g} / \mathrm{L}$ ethanol. Acetic acid (2.88 g) accumulated under this condition. As a result, the total conversion reached $0.44 \mathrm{~g} / \mathrm{g}$ glycerol (Table 4). Under aerobic conditions, glycerol consumption and ethanol production were boosted to 1.29 and $0.5 \mathrm{~g} \cdot \mathrm{L} \cdot \mathrm{h}$, respectively. The efficiency of ethanol conversion was $0.39 \mathrm{~g}^{\mathrm{e}} / \mathrm{g}^{\mathrm{g}}$, and the total convertibility was $0.45 \mathrm{~g}^{\mathrm{e}} / \mathrm{g}^{\mathrm{g}}$, which represents $90 \%$ of the theoretical conversion without considering the glycerol utilized in cell formation (Table 4). ["(Table 4)"] Interestingly, the metabolic engineering here changed the nature of the D452-2 strain from non-grower on glycerol to a grower growing at the rate of $0.045 / \mathrm{h}$ (Fig. S2) when starting from an initial inoculum of 0.01 , thereby confirming the importance of supplementation of YNB medium with $10 \times 20 \mathrm{mg} / \mathrm{L}$ leucine and histidine in a $50 \mathrm{~mL}$ Falcon tube. Growth was also observed during the ethanolic conversion of glycerol before a slight decrease at the onset of the conversion (Fig. S3). A similar tendency was observed during monitoring growth with supplementation of $1 \times 20 \mathrm{mg} / \mathrm{L} \mathrm{mg} / \mathrm{L}$ leucine and histidine (data not shown). These results suggested that the D452-2 strain was significantly affected by the supplementation levels of histidine and leucine. This observation is supported by a recent study showing a crucial role of amino acid content in cell growth (36). Biosynthesis of NAD ${ }^{+}$from tryptophan via the kynurenine pathway is well known $(37,38)$. In addition, nicotinic acid, nicotinamide, quinolinic acid, and nicotinamide riboside can salvage $\mathrm{NAD}^{+}$biosynthesis. In this context, nicotinic acid is auxotrophic under anaerobic conditions in S. cerevisiae (38). Together, these limitations may explain the lower production titers, conversion rates, and efficiency in YNB compared to that in the YP medium by the engineered strain. In addition, the other remarkable difference between 
YNB and YP media is the increased accumulation of acetic acid in YNB (from $14 \mathrm{mg}$ to $53 \mathrm{mg}$ acetic acid/g glycerol) under semi-aerobic conditions (Tables 3, 4). One of the theories assumes a competition between aldehyde dehydrogenase $(S c A L D)$ and $O p G D H$ for $\mathrm{NAD}^{+}$; however, further studies are required to clarify this point. The inability to ferment glycerol under strict anaerobic conditions (Table 4) indicates the lack of renovation shuttles in the absence of oxygen and oxidizing agents. Hence, recycling of $\mathrm{NADH} / \mathrm{NAD}^{+}$represents the complementary factor for robust oxidation via the DHA pathway and efficient utilization of glycerol to produce bioethanol or other bio-based chemicals. We are currently designing metabolic engineering strategies for glycerol fermentation under anaerobic conditions, while using the high reduction ability of glycerol to improve the fermentation efficiency of lignocellulose sugars. In addition, we intend to determine the amino acids that may play a significant role in the defined media to reach production level of complex medium.

In summary, we presented an efficient model that comprehensively controlled glycerol traffic to ethanol in S. cerevisiae. This model of systematic metabolic engineering included integration of the following: (i) robust expression of all genes involved in the DHA pathway; (ii) predominant glycerol oxidation by an oxygen-dependent dynamic of the water-forming NADH oxidase LINoxE, which controls the reaction stoichiometry with the regeneration of the cofactor $\mathrm{NAD}^{+}$; (iii) elimination of the first step of both glycerol biosynthesis and glycerol catabolism via G3P. Our study provides an innovative metabolic engineering strategy for re-routing glycerol traffic in S. cerevisiae, while tracking ethanol production to levels that have not yet been attained within any other safe model organism, either native or genetically engineered $(8,12,14,39-41)$. The metabolic engineering strategy represents another pivotal step for fermenting glycerol in 
several promising biorefinery scenarios by co-converting glycerol with the saccharified glucose to ethanol after glycerolysis pretreatment of recalcitrant lignocellulosic biomass.

\section{MATERIALS AND METHODS}

Strains, primers, cassettes, and plasmid construction. All the strains used in this study (Table 1) were derived from the laboratory strain D452-2 (17), and their original strains are shown in Fig. S1. The plasmids used in this study are listed in Table 5. The primers used are listed in Table S1. The primers used for obtaining the native genes were designed based on the sequences available in the S288C Saccharomyces Genome Database. The details of the DNA fragments and cassettes, and the construction of plasmids are mentioned as follows. ["(Table 5)"]

\section{Construction of TDH3-DIT1 ${ }_{\mathrm{d} 22}$-URA3, TDH3-GDH-DIT1 ${ }_{\mathrm{d} 22}$-URA3, and TDH3-NoxE-}

DIT1 $1_{\text {d22 }}$-URA3 plasmids. Initially, D452-2 cells picked using a toothpick were resuspended in a polymerase chain reaction (PCR) tube containing $20 \mu \mathrm{L}$ of $30 \mathrm{mM} \mathrm{NaOH}$ (Wako, Osaka, Japan) and heated at $95^{\circ} \mathrm{C}$ for $10 \mathrm{~min}$ in PCR (Astec thermal cycler-GeneAtlas, Japan). Next, $1 \mu \mathrm{L}$ of the disrupted cells was used as a template for a $50 \mu \mathrm{L}$ reaction. High-fidelity polymerase KODplus neo (Toyobo, Osaka, Japan) was used to obtain the TDH3 promoter with an extra region of 52 base pairs (bp) complementary to the upstream sequence of the start codon of ScGPD1 (fragment 1). The mutated terminator $D I T 1_{d 22}$ was purchased from Integrated DNA Technology (IDT; Tokyo, Japan) (21) and then amplified to generate an extra region (46 bp) corresponding to the downstream sequence of the stop codon of $S c G P D 1$ (fragment 2). Thereafter, the fragments were restricted using XhoI and NotI (Takara, Shiga, Japan) for the first fragment and NotI and Sall for the second fragment. Then, the DNA was purified using the FastGene Gel/PCR extraction kit (Nippon Genetics, Tokyo, Japan). One-step cloning was used to clone the TDH3 
promoter and mutated $D I T 1_{d 22}$ terminator into the XhoI/SalI sites of the PGK-URA3 plasmid to construct the TDH3-DIT1 ${ }_{\mathrm{d} 22}-\mathrm{URA} 3$ plasmid (Table 5). The $O p G D H$ gene was purchased from IDT (GenBank accession number XP_018210953.1) (Table S2). NotI/BamHI sites were added to $O p G D H$ via PCR and then cleaved by restriction enzymes to form the TDH3-GDH-DIT1 $1_{\mathrm{d} 22^{-}}$ URA3 plasmid (Table 5). Similarly, LINoxE (accession number AAK04489.1) was prepared as described above. The sequence is also shown in Table S2 and was prepared as described earlier. The plasmid was then cloned into the TDH3-DIT1 $1_{\mathrm{d} 22}$-URA3 plasmid to assemble the TDH3NoxE-DIT1 $1_{\mathrm{d} 22}$-URA3 plasmid (Table 5).

Construction of the multiplex pCAS-gRNA-CRISPR system. The original multiplex pCASgRNA system was a gift from Prof. Jamie Cate (42). The online tool https://crispr.dbcls.jp/ was used for the rational design of the CRISPR/Cas target (43). The efficiency of the target design was also confirmed using https://chopchop.cbu.uib.no/. Accordingly, a highly specific guide, 20 base pairs (bp) before the protospacer adjacent motif (PAM), was selected and used to design the primers (Table S1). Instead of a single-step amplification of the entire multiplex plasmid, which could result in mutations, two rounds of polymerization were used to produce only universal scaffolds. In the first round, the two fragments were synthesized separately. The first fragment encompassed the upstream region of the guide RNA (gRNA) scaffold, while the second one encompassed the downstream region (Fig. S4). After purifying each DNA segment, the overlapping gRNA (20-nucleotide guide sequence) was used to generate overhangs during the second round of PCR (Fig. S4). During the second PCR, KOD-plus neo, pCAS F, and R primers were used with 6 picograms of each DNA segment as a template. Then, the unified DNA fragment was cleaved by SmaI/PstI to form SmaI-universal scaffold-PstI. Subsequently, the universal scaffold was cloned into a multiplex plasmid, and its analogous part was detached. As 
a result, a new multiplex pCAS-gRNA plasmid was formed. These steps were repeated for the construction of multiplex pCAS-gRNA plasmids targeting ScGPD1 and ScGUT1 (Table 5). The sequences of the new SmaI-universal scaffold-PstI in the constructed plasmids were confirmed via sequencing.

\section{Construction of pPGK-DAK1-URA3, pPGK-DAK2-URA3, pPGK-TPI1-URA3, pPGK-} TPI1-DAK2-URA3, and pPGK-TPI1-DAK2-DAK1-URA3 plasmids. $D A K 1, D A K 2$, and TPI1 were obtained from genomic DNA of the parent strain D452-2, as mentioned above. The Xhol site of $S c D A K 2$ was disrupted by incorporating a silent mutation before cloning. The ends of the genes were cleaved using the restriction enzymes, sites of which were present in the supplemented primers (Table S1, section 1). First, each gene was separately cloned in the pPGKURA3 plasmid (44) under the $P G K$ promoter and terminator (Table 5). After cloning, the sequence of the genes was confirmed using the primers listed in Table S1. To construct the pPGK-TPI1-DAK2-URA3 plasmid, the XhoI/SalI-ScDAK2 cassette was inserted in the SalI site of the pPGK-TPI1-URA3 plasmid after dephosphorylation of the site. Since the previous ligation of SalI with XhoI altered the sequence of the ligation site, preventing its cleavage and detachment of the cloned cassettes, XhoI/SalI-ScTPII or ScDAK1, we reused the SalI site during the cloning of the XhoI/SalI-ScDAK2 cassette. The plasmid pPGK-TPI1-DAK2-DAK1-URA3 was then constructed (Table 5).

\section{Construction of pAUR101-PGK-RPL41B, pAUR101-FPS1, and pAUR101-FPS1-TPI1-}

DAK2-DAK1 plasmids. Candida utilis (NBRC 0988) was obtained from the National Biological Resource Center (NBRC) of the National Institute of Technology and Evaluation (Japan) and was used as a source of the glycerol facilitator (CuFPS1). The sequence of CuFPS1, 
311 which was included in the deposited gene bank under the accession number BAEL01000108.1,

312 is shown in Table S2, along with its expression system, including the PGK promoter and

313 RPL41B terminator. To construct the pAUR101-PGK-RPL41B plasmid, the pAUR101 vector

314 (Takara, Shiga, Japan) was subjected to one step of cloning of the SmaI-PGK-Not1 and NotI-

315 RPL41B-SacI fragments into its SmaI-SacI sites. Thereafter, CuFPS1 was cloned into a

316 dephosphorylated NotI site of pAUR101-PGK-RPL41B to assemble the pAUR101-FPS1 vector.

317 The direction of cloning was confirmed using PCR. Then, a detached set of cassettes,

318 ScTPI1, ScDAK2, and ScDAK1, obtained via Xhol-SalI digestion from the previously

319 constructed plasmid, pPGK-TPI1-DAK2-DAK1-URA3, was cloned into the dephosphorylated

320 SalI site of the pAUR101-FPS1 vector to assemble the pAUR101-FPS1-TPI1-DAK2-DAK1

321 plasmid (Table 5).

Construction of the M1 and pAUR101-M1 plasmids. All fragments constituting this module were first obtained separately via PCR (Fig. 3). CuFPS1, $O p G D H$, and the mutated $D I T 1_{d 22}$ terminator were amplified from their synthetic DNA stocks, while the other fragments were amplified from the genomic DNA of the D452-2 strain. Following the generation of 12 fragments via PCR, the products were electrophoresed on $1 \%$ or $2 \%$ agarose gel, excised according to the size of fragments, and purified using an extraction kit (Nippon Genetics, Tokyo, Japan). The highly purified fragments were used for assembly using the Gibson assembly master mix (New England Biolabs, Tokyo, Japan). First, three consecutive segments were joined

330 seamlessly according to the manufacturer's protocol (Gibson), followed immediately by PCR for

331 the next consecutive three segments, which were then purified again from agarose gel. Six 332 sequential segments were assembled via Gibson assembly and PCR to assemble the whole 
FBA1p-ScTPI1-TDH3t (Fig. 3). The SacI site was added upstream of module M1, while the SmaI site was added downstream for cloning into the pAUR101 vector to form pAUR 101-M1 (Table 5). Finally, the vector pAUR 101-M1 was transformed into Escherichia coli as described above, and the accurate structure of M1 was confirmed by sequencing the whole module M1 in the pAUR-M1 vector.

Transformation and recombination of strains. All constructed plasmids were transformed in $E$. coli NEB 10-beta via the heat shock method of transformation according to the manufacturer's instructions (New England Biolabs, Tokyo, Japan). All plasmids were extracted using the QIAprep Spin miniprep kit (QIAGEN, Hilden, Germany). All DNA measurements were performed using a BioSpec-nano (Shimadzu, Japan). Plasmids and DNA fragments were stored at $20{ }^{\circ} \mathrm{C}$. Yeast transformation was performed using the $\mathrm{Fast}^{\mathrm{TM}}$ yeast transformation kit (G-Biosciences, USA) to integrate the linear pAUR101 vector. BsiWI (New England Biolabs, Tokyo, Japan) was used to linearize the $A U R I-C$ gene before the transformation, which was integrated in the AURl locus of $S$. cerevisiae via homologous recombination. Positive colonies were selected on aureobasidin A (Takara, Shiga, Japan), and further confirmed via PCR. The same method and kit were used to transform the linearized pPGK-URA3 plasmid, in which URA3 was linearized with NcoI (Takara, Shiga, Japan). The transformants were grown on Yeast Nitrogen Base (YNB) medium supplemented with $20 \mathrm{mg} / \mathrm{L}$ leucine and histidine; the fastgrowing colonies were confirmed using PCR and then screened for glycerol consumption and ethanol production. $S c G P D 1$ with $O p G D H$ were replaced via homologous repair of the doublestrand break, which was induced by CRISPR Cas 9 (45). Similarly, ScGUT1 was substituted by the M1 module. The homologous regions were further extended via PCR during double-strand DNA repair. Positive colonies were confirmed via PCR using primers located on the inserted 
cassettes and regions upstream and downstream of the flanking recombined loci. The recombinant cells were re-confirmed after loss of the pCAS multiplex plasmids. All the recombinant strains and their genotypes are listed in Table 1.

Cultivation of yeast cells. Yeast peptone dextrose (YPD) medium was routinely used for the maintenance and cultivation of strains listed in Table 5 on solid agar or in liquid media. All liquid cultivation was conducted under micro-aerobic conditions $(10 \mathrm{~mL}$ culture in $50 \mathrm{~mL}$ Falcon tubes with 200 rpm of orbital shaking (TAITEC, BioShaker BR-42FL, Japan) and approximately $45^{\circ}$ sitting angle) overnight at $30^{\circ} \mathrm{C}$. The screw caps of the tubes were closed at a level that permitted $\mathrm{CO}_{2}$ escape. Under these conditions, the optical densities $\left(\mathrm{OD}_{600}\right)$ of the strains varied between 6 and 9 (Fig. S5). The cell densities were monitored at $600 \mathrm{~nm}$ after ten-fold dilution using a spectrophotometer (AS ONE, Japan). $\mathrm{YPD}_{15} \mathrm{G}_{70}$ medium [(w/v) $1.5 \%$ glucose and 6\% glycerol] was used for preculturing the cells, as shown in Tables 2 and 3. In addition, it was used during cultivation of the cells, which were used for preparing the cell-free extracts and determining the $\mathrm{NAD}^{+} / \mathrm{NADH}$ ratios. YNB medium supplemented with $1 \times 20 \mathrm{~g} / \mathrm{L}$ glucose, 20 $\mathrm{mg} / \mathrm{L}$ leucine, and histidine was used to culture the recombinant strains harboring active URA3 during or after the transformation.

Preparation of cell-free extract. Proteins were extracted as described previously $(22,46,47)$ with some modifications as follows: $10 \mathrm{~mL}$ cell culture of approximately $\mathrm{OD}_{600}=5$ was harvested via centrifugation at $700 \times g$ for 2 min at $4{ }^{\circ} \mathrm{C}$. The cell pellets were washed twice with 20 and $1 \mathrm{~mL}$ of $100 \mathrm{mM}$ HEPES buffer (pH 7.4). Then, the cell pellets were lysed in $1 \mathrm{~mL}$ HEPES buffer supplemented with $1 \mathrm{mM} \mathrm{MgCl}_{2}$ and $10 \mathrm{mM}$ 2-mercaptoethanol with approximately $400 \mathrm{mg}$ glass beads in a $2 \mathrm{~mL}$ Eppendorf tube. The lysis was accomplished by 
vigorous shaking using a bench vortex with six time intervals on ice for $30 \mathrm{~s}$. The crude proteins were separated from the glass beads and cell debris via two rounds of centrifugation at $22,300 \times$ $g$ at $4{ }^{\circ} \mathrm{C}$ for $5 \mathrm{~min}$. The total protein concentration of the supernatant was estimated using Quick Start ${ }^{\mathrm{TM}}$ Bradford (Bio-Rad, USA) and bovine serum albumin standards (Novagen, USA) at 595 nm using Infinite M200 (Tecan, Switzerland).

Enzyme assays. The specific activity of glycerol dehydrogenase was assayed by monitoring the changes in NADH absorbance at $340 \mathrm{~nm}$ (UV-2700; UV-VIS spectrophotometer, Shimadzu, Japan). One milliliter mixture of $79 \mathrm{mM}$ HEPES buffer (pH 7.4), $10 \mu \mathrm{L}$ crude extract, and 10 $\mathrm{mM} \mathrm{NAD}{ }^{+}$were mixed in the quartz cuvette and incubated for $30 \mathrm{~s}$ to complete any side reaction and obtain a stable baseline. The reaction was initiated by adding $100 \mu \mathrm{L}$ of $1 \mathrm{M}$ glycerol and incubating for $1 \mathrm{~min}$. The activity of ScTPIl was assayed as described previously (48), with some modifications. The reaction mixture consisted of $100 \mathrm{mM}(\mathrm{pH} 7.53)$ triethanolamine hydrochloride (Sigma-Aldrich), $10 \mathrm{mM}$ dihydroxyacetone phosphate (DHAP) hemimagnesium salt (Sigma-Aldrich), $100 \mu \mathrm{L}$ crude extract, and $5 \mathrm{mM} \mathrm{NAD}^{+}$as a starting point for the reaction, which lasted $400 \mathrm{~s}$. The main changes in absorbance were detected after approximately $100 \mathrm{~s}$. Changes in the absorbance from $200 \mathrm{~s}$ to $260 \mathrm{~s}$ were used to calculate the activities.

Dihydroxyacetone kinase was assayed using a universal kinase activity kit according to the manufacturer's instructions (R\&D systems, EA004, USA).

\section{Determination of the intracellular concentration of $\mathrm{NADH} / \mathrm{NAD}^{+}$. NADH/NAD ${ }^{+}$was} estimated as reported previously (24). Twenty microliters of cultivated cells of $\mathrm{OD}_{600}=5$ were harvested via centrifugation at $1600 \times g$ for 2 min at $4{ }^{\circ} \mathrm{C}$. The $\mathrm{NADH} / \mathrm{NAD}^{+}$ratio was 
400 determined per the instructions of the EnzyChrom ${ }^{\mathrm{TM}} \mathrm{NAD}^{+} / \mathrm{NADH}$ assay kit (BioAssay Systems $401 \quad($ E2ND-100)).

402 Fermentation. Fermentations were performed with orbital shaking (TAITEC, BioShaker BR403 42FL, Japan) at different levels of oxygen availability in the flask based on the ratio of liquid 404 medium $(\mathrm{mL})$ : Erlenmeyer flask volume $(\mathrm{mL})$, namely, micro-aerobic (20:100), semi-aerobic 405 (20:200), and aerobic (20:300). The cell pellets were obtained from approximately $20 \mathrm{~mL}$ cell 406 culture $\left(\mathrm{OD}_{600}=4\right)$, which was harvested from appropriate volumes of preculture via 407 centrifugation at $1,600 \times g$ for $5 \mathrm{~min}$ and then washed with $20 \mathrm{~mL}$ Milli-Q water. The alcoholic conversion of glycerol was conducted at $30{ }^{\circ} \mathrm{C}$ with agitation speeds of 180 or $200 \mathrm{rpm}$. The YP and YNB media were supplemented with glycerol or glucose of different initial concentrations, which listed in Fig. 2, Table 3, and the legend of Table 4, in accordance with those obtained after

411 the glycerolysis of biomass (16). The initial concentrations of glycerol or glucose are shown in 412 Tables 3 and 4 and Fig. 2. For fermentation under strict anaerobic conditions, 50 mL Mighty vials were sterilized with a precision seal septum cap prior to inoculation of the cell pellets and 414 YNB medium. Then, nitrogen gas was flushed into the medium through Terumo needles, which 415 were also used for sampling.

416 Fermentation analysis. The samples $(100 \mu \mathrm{L})$ were picked from fermentative flasks under 417 sterile conditions, diluted with $900 \mu \mathrm{L}$ Milli-Q water in Eppendorf tubes, and mixed before 418 centrifugation at $22,300 \times g$ for $5 \mathrm{~min}$. Subsequently, the supernatants were decanted using a 1 $419 \mathrm{~mL}$ syringe and filtered through a $0.45 \mu \mathrm{m}$ hydrophilic filter (PTFE) directly into new $2 \mathrm{~mL}$ high 420 performance liquid chromatography (HPLC) glass vials. Analyses were performed using HPLC 421 (Shimadzu, Japan) on an Aminex HPX-87H column (Bio-Rad Laboratories, Hercules, CA, USA) 
connected to refractive index (RID-10A; Shimadzu) and prominence diode array (SPD-M20A;

Shimadzu) detectors using $5 \mathrm{mM} \mathrm{H}_{2} \mathrm{SO}_{4}$ as the mobile phase at $50{ }^{\circ} \mathrm{C}$ with a flow rate of 0.6

$\mathrm{mL} / \mathrm{min}$. Glucose, glycerol, ethanol, acetic acid, pyruvate, succinic acid, and acetaldehyde were monitored using RID. DHAP and DHA levels were quantified using a prominence diode array detector (SPD-M20A).

Data availability: All necessary data required to assess our findings are available in this manuscript or its supplementary data. Further details related to this article may be requested from the authors.

\section{ACKNOWLEDGMENTS}

Funding: This work was supported by a Mission 5-2 Research Grant from the Research Institute for Sustainable Humanosphere, Kyoto University.

Author contributions: S.M.R.K. conceived the research idea, and planned the experiments.

S.M.R.K. also provided information regarding procurement of strains, chemicals, and toolboxes for genetic engineering, performed the experiments, and analyzed the results. S.M.R.K. wrote, revised, and submitted the manuscript. T.W. was responsible for all financial support and provided all the chemicals and equipment. T.W. was involved in formulating the research idea, planning and organization, discussion of the results, and manuscript revision and submission.

\section{COMPETING INTERESTS}

The authors declare that there are no competing interests. 


\section{REFERENCES}

1. Nomanbhay S, Hussein R, Ong MY. 2018. Sustainability of biodiesel production in Malaysia by production of bio-oil from crude glycerol using microwave pyrolysis: a review. Green Chemistry Letters and Reviews 11(2):135-157. https://doi.org/10.1080/17518253.2018.1444795.

2. Yazdani SS, Gonzalez R. 2007. Anaerobic fermentation of glycerol: a path to economic viability for the biofuels industry. Current Opinion in Biotechnology 18(3):213-219. https://doi.org/10.1016/j.copbio.2007.05.002.

3. Sprague GF, Cronan JE. 1977. Isolation and characterization of Saccharomyces cerevisiae mutants defective in glycerol catabolism. Journal of Bacteriology 129(3):1335-1342. https://doi.org/10.1128/JB.129.3.1335-1342.1977.

4. Ansell R, Granath K, Hohmann S, Thevelein JM, Adler L. 1997. The two isoenzymes for yeast $\mathrm{NAD}^{+}$-dependent glycerol 3-phosphate dehydrogenase encoded by GPD1 and GPD2 have distinct roles in osmoadaptation and redox regulation. The EMBO Journal 16(9):21792187. https://doi.org/10.1093/emboj/16.9.2179.

5. Grauslund M, Lopes JM, Rønnow B. 1999. Expression of GUT1, which encodes glycerol kinase in Saccharomyces cerevisiae, is controlled by the positive regulators Adr1p, Ino2p and Ino4p and the negative regulator Opi1p in a carbon source-dependent fashion. Nucleic Acids Research 27(22):4391-4398. https://doi.org/10.1093/nar/27.22.4391.

6. Grauslund M, Rønnow B. 2000. Carbon source-dependent transcriptional regulation of the mitochondrial glycerol-3-phosphate dehydrogenase gene, GUT2, from Saccharomyces cerevisiae. Canadian Journal of Microbiology 46(12):1096-1100. https://doi.org/10.1139/w00-105. 
7. Turcotte B, Liang XB, Robert F, Soontorngun N. 2010. Transcriptional regulation of nonfermentable carbon utilization in budding yeast. FEMS Yeast Research 10(1):2-13. https://doi.org/10.1111/j.1567-1364.2009.00555.x.

8. Yu KO, Kim SW, Han SO. 2010. Engineering of glycerol utilization pathway for ethanol production by Saccharomyces cerevisiae. Bioresource Technology 101(11):4157-4161. https://doi.org/10.1016/j.biortech.2010.01.066.

9. Swinnen S, Klein M, Carrillo M, McInnes J, Nguyen HTT, Nevoigt E. 2013. Reevaluation of glycerol utilization in Saccharomyces cerevisiae: characterization of an isolate that grows on glycerol without supporting supplements. Biotechnology for Biofuels 6(1):157. https://doi.org/10.1186/1754-6834-6-157.

10. Swinnen S, Ho PW, Klein M, Nevoigt E. 2016. Genetic determinants for enhanced glycerol growth of Saccharomyces cerevisiae. Metabolic Engineering 36:68-79. https://doi.org/10.1016/j.ymben.2016.03.003.

11. Klein M, Carrillo M, Xiberras J, Islam ZU, Swinnen S, Nevoigt E. 2016. Towards the exploitation of glycerol's high reducing power in Saccharomyces cerevisiae-based bioprocesses. Metabolic Engineering 38:464-472. https://doi.org/10.1016/j.ymben.2016.10.008.

12. Aßkamp MR, Klein M, Nevoigt E. 2019. Saccharomyces cerevisiae exhibiting a modified route for uptake and catabolism of glycerol forms significant amounts of ethanol from this carbon source considered as 'non-fermentable'. Biotechnology for Biofuels 12:257. https://doi.org/10.1186/s13068-019-1597-2.

13. Xiberras J, Klein M, Nevoigt E. 2019. Glycerol as a substrate for Saccharomyces cerevisiae based bioprocesses-Knowledge gaps regarding the central carbon catabolism of 
this 'non-fermentable' carbon source. Biotechnology Advances 37(6):107378. https://doi.org/10.1016/j.biotechadv.2019.03.017.

14. Semkiv M, Kata I, Ternavska O, Sibirny W, Dmytruk K, Sibirny A. 2019.

Overexpression of the genes of glycerol catabolism and glycerol facilitator improves glycerol conversion to ethanol in the methylotrophic thermotolerant yeast Ogataea polymorpha. Yeast 36(5):329-339. https://doi.org/10.1002/yea.3387.

15. Liu J, Takada R, Karita S, Watanabe T, Honda Y, Watanabe T. 2010. Microwaveassisted pretreatment of recalcitrant softwood in aqueous glycerol. Bioresource Technology 101(23):9355-9360. https://doi.org/10.1016/j.biortech.2010.07.023.

16. Ohashi Y, Watanabe T. 2018. Catalytic performance of food additives alum, flocculating agent, $\mathrm{Al}\left(\mathrm{SO}_{4}\right)_{3}, \mathrm{AlCl}_{3}$, and other lewis acids in microwave solvolysis of hardwoods and recalcitrant softwood for biorefinery. ACS Omega 3(11):16271-16280. https://doi.org/10.1021/acsomega.8b01454.

17. Hosaka K, Nikawa J, Kodaki T, Yamashita S. 1992. A dominant mutation that alters the regulation of INO1 expression in Saccharomyces cerevisiae. Journal of Biochemistry 111(3):352-358. https://doi.org/10.1093/oxfordjournals.jbchem.a123761.

18. Hosaka K, Murakami T, Kodaki T, Nikawa J, Yamashita S. 1990. Repression of choline kinase by inositol and choline in Saccharomyces cerevisiae. Journal of Bacteriology 172(4):2005-2012. https://doi.org/10.1128/jb.172.4.2005-2012.1990.

19. Kodaki T, Yamashita S. 1989. Characterization of the methyltransferases in the yeast phosphatidylethanolamine methylation pathway by selective gene disruption. European Journal of Biochemistry 185(2):243-251. https://doi.org/10.1111/j.14321033.1989.tb15109.x. 
20. Yamada-Onodera K, Yamamoto H, Emoto E, Kawahara N, Tani Y. 2002. polymorpha DL-1, and its gene cloning. Acta Biotechnologica 22(ㅆ/4):337-353. https://doi.org/10.1002/1521-3846(200207)22:3/4<337::AID-ABIO337>3.0.CO;2-6

Matsuyama T. 2016. Enhancement of protein production via the strong DIT1 terminator and

22. Nguyen HT, Nevoigt E. 2009. Engineering of Saccharomyces cerevisiae for the production of dihydroxyacetone (DHA) from sugars: a proof of concept. Metabolic Engineering

23. Aßkamp MR, Klein M, Nevoigt E. 2019. Involvement of the external mitochondrial NADH dehydrogenase Nde1 in glycerol metabolism by wild-type and engineered Saccharomyces cerevisiae strains. FEMS Yeast Research 19(3):3. https://doi.org/10.1093/femsyr/foz026.

24. Bae SJ, Kim S, Hahn JS. 2016. Efficient production of acetoin in Saccharomyces cerevisiae by disruption of 2,3-butanediol dehydrogenase and expression of NADH oxidase. Scientific Reports 6:27667. https://doi.org/10.1038/srep27667.

25. Vemuri GN, Eiteman MA, McEwen JE, Olsson L, Nielsen J. 2007. Increasing NADH oxidation reduces overflow metabolism in Saccharomyces cerevisiae. Proceedings of the National Academy of Sciences of the United States of America 104(7):2402-2407. https://doi.org/10.1073/pnas.0607469104.

26. Kim JW, Seo SO, Zhang GC, Jin YS, Seo JH. 2015. Expression of Lactococcus lactis NADH oxidase increases 2,3-butanediol production in Pdc-deficient Saccharomyces 
cerevisiae. Bioresource Technology 191:512-519. https://doi.org/10.1016/j.biortech.2015.02.077.

27. Kim S, Hahn JS. 2015. Efficient production of 2,3-butanediol in Saccharomyces cerevisiae by eliminating ethanol and glycerol production and redox rebalancing. Metabolic Engineering 31:94-101. https://doi.org/10.1016/j.ymben.2015.07.006.

28. Kim JW, Lee YG, Kim SJ, Jin YS, Seo JH. 2019. Deletion of glycerol-3-phosphate dehydrogenase genes improved 2,3-butanediol production by reducing glycerol production in pyruvate decarboxylase-deficient Saccharomyces cerevisiae. Journal of Biotechnology 304:31-37. https://doi.org/10.1016/j.jbiotec.2019.08.009.

29. Murata K, Fukuda Y, Watanabe K, Saikusa T, Shimosaka M, Kimura A. 1985. Characterization of methylglyoxal synthase in Saccharomyces cerevisiae. Biochemical and Biophysical Research Communications 131(1):190-198. https://doi.org/10.1016/0006291x(85)91788-7.

30. Zheng Z, Zou J. 2001. The initial step of the glycerolipid pathway: identification of glycerol 3-phosphate/dihydroxyacetone phosphate dual substrate acyltransferases in Saccharomyces cerevisiae. The Journal of Biological Chemistry 276(45):41710-41716. https://doi.org/10.1074/jbc.M104749200.

31. Overkamp KM, Bakker BM, Kötter P, Luttik MA, Van Dijken JP, Pronk JT. 2002. Metabolic engineering of glycerol production in Saccharomyces cerevisiae. Applied and Environmental Microbiology 68(6):2814-2821. https://doi.org/10.1128/aem.68.6.28142821.2002. 
32. Molin M, Norbeck J, Blomberg A. 2003. Dihydroxyacetone kinases in Saccharomyces cerevisiae are involved in detoxification of dihydroxyacetone. The Journal of Biological Chemistry 278(3):1415-1423. https://doi.org/10.1074/jbc.M203030200.

33. Lutstorf U, Megnet R. 1968. Multiple forms of alcohol dehydrogenase in Saccharomyces cerevisiae. I. Physiological control of ADH-2 and properties of ADH-2 and ADH-4. Archives of Biochemistry and Biophysics 126(3):933-944. https://doi.org/10.1016/00039861(68)90487-6.

34. Ito Y, Yamanishi M, Ikeuchi A, Imamura C, Tokuhiro K, Kitagawa T, Matsuyama T. 2013. Characterization of five terminator regions that increase the protein yield of a transgene in Saccharomyces cerevisiae. Journal of Biotechnology 168(4):486-492. https://doi.org/10.1016/j.jbiotec.2013.09.024.

35. Wei L, Wang Z, Zhang G, Ye B. 2017. Characterization of terminators in Saccharomyces cerevisiae and an exploration of factors affecting their strength. Chembiochem: a European Journal of Chemical Biology 18(24):2422-2427. https://doi.org/10.1002/cbic.201700516.

36. Roberts TM, Kaltenbach HM, Rudolf F. 2020. Development and optimisation of a defined high cell density yeast medium. Yeast 37(5-6):336-347. https://doi.org/10.1002/yea.3464.

37. Panozzo C, Nawara M, Suski C, Kucharczyka R, Skoneczny M, Bécam AM, Rytka J, Herbert CJ. 2002. Aerobic and anaerobic NAD ${ }^{+}$metabolism in Saccharomyces cerevisiae. FEBS Letters 517(1-3):97-102. https://doi.org/10.1016/s0014-5793(02)02585-1.

38. Kato M, Lin SJ. 2014. Regulation of $\mathrm{NAD}^{+}$metabolism, signaling and compartmentalization in the yeast Saccharomyces cerevisiae. DNA Repair 23:49-58. https://doi.org/10.1016/j.dnarep.2014.07.009. 
39. Shams Yazdani SS, Gonzalez R. 2008. Engineering Escherichia coli for the efficient conversion of glycerol to ethanol and co-products. Metabolic Engineering 10(6):340-351. https://doi.org/10.1016/j.ymben.2008.08.005.

40. Trinh CT, Srienc F. 2009. Metabolic engineering of Escherichia coli for efficient conversion of glycerol to ethanol. Applied and Environmental Microbiology 75(21):66966705. https://doi.org/10.1128/AEM.00670-09.

41. Loaces I, Rodríguez C, Amarelle V, Fabiano E, Noya F. 2016. Improved glycerol to ethanol conversion by E. coli using a metagenomic fragment isolated from an anaerobic reactor. Journal of Industrial Microbiology and Biotechnology 43(10):1405-1416. https://doi.org/10.1007/s10295-016-1818-7.

42. Ryan OW, Skerker JM, Maurer MJ, Li X, Tsai JC, Poddar S, Lee ME, DeLoache W, Dueber JE, Arkin AP, Cate JH. 2014. Selection of chromosomal DNA libraries using a multiplex CRISPR system. eLife 3:e03703. https://doi.org/10.7554/eLife.03703.

43. Naito Y, Hino K, Bono H, Ui-Tei K. 2015. CRISPRdirect: software for designing CRISPR/Cas guide RNA with reduced off-target sites. Bioinformatics 31(7):1120-1123. https://doi.org/10.1093/bioinformatics/btu743.

44. Kang YS, Kane J, Kurjan J, Stadel JM, Tipper DJ. 1990. Effects of expression of mammalian $\mathrm{G}$ alpha and hybrid mammalian-yeast $\mathrm{G}$ alpha proteins on the yeast pheromone response signal transduction pathway. Molecular and Cellular Biology 10(6):2582-2590. https://doi.org/10.1128/mcb.10.6.2582.

45. Ryan OW, Poddar S, Cate JH. 2016. CRISPR-Cas9 genome engineering in Saccharomyces cerevisiae cells. Cold Spring Harbor Protocols 2016(6). 10.1101/pdb.prot086827. https://doi.org/10.1101/pdb.prot086827. 
600

601

602

603

604

605

606

607

608

609

610

611

612

46. Khattab SM, Saimura M, Kodaki T. 2013. Boost in bioethanol production using recombinant Saccharomyces cerevisiae with mutated strictly NADPH-dependent xylose reductase and NADP(+)-dependent xylitol dehydrogenase. Journal of Biotechnology 165(34):153-156. https://doi.org/10.1016/j.jbiotec.2013.03.009.

47. Khattab SMR, Kodaki T. 2014. Efficient bioethanol production by overexpression of endogenous Saccharomyces cerevisiae xylulokinase and NADPH-dependent aldose reductase with mutated strictly $\mathrm{NADP}^{+}$-dependent Pichia stipitis xylitol dehydrogenase. Process Biochemistry 49(11):1838-1842. https://doi.org/10.1016/j.procbio.2014.07.017.

48. Plaut B, Knowles JR. 1972. pH-dependence of the triose phosphate isomerase reaction. The Biochemical Journal 129(2):311-320. https://doi.org/10.1042/bj1290311.

48. Kang YS, Kane J, Kurjan J, Stadel JM, Tipper DJ. 1990. Effects of expression of mammalian $\mathrm{G}$ alpha and hybrid mammalian-yeast $\mathrm{G}$ alpha proteins on the yeast pheromone response signal transduction pathway. Molecular and Cellular Biology 10(6):2582-2590. https://doi.org/10.1128/mcb.10.6.2582. 


\section{FIGURE LEGENDS}

614

615

Fig. 1. Schematic showing the integrative scenario of a biorefinery with new generation of glycerol-fermenting yeast and redirection of glycerol influxes to ethanol production in Saccharomyces cerevisiae via retrofitted native glycerol anabolic and catabolic pathways using the robust oxidative route with restoration of the $\mathrm{NAD}^{+}$cofactor via $\mathrm{O}_{2}$-dependent dynamics of water-forming NADH oxidase. During pathway re-routing, glycerol-3-phosphate dehydrogenase 1 (ScGPD1) and glycerol kinase 1 (GUT1) were knocked out. Highlighted circle indicates the overexpressed indigenous $S$. cerevisiae enzymes dihydroxyacetone kinase (ScDAK) 1 and 2, as well as triosephosphate isomerase (ScTPI) 1, heterologous glycerol dehydrogenase from Ogataea polymorpha $(O p G D H)$, glycerol facilitator from Candida utilis (CuFPS1), and water-forming NADH oxidase from Lactococcus lactis subsp. lactis Il1403 (LINoxE).

Fig. 2. Comparison of the time course of glycerol-glucose fermentation between the S. cerevisiae strains used in this study. Reference ancestral strain (square); NOXE strain (plus); GDH strain (rhomboid); GN strain (asterisk); GN-FDT strain (triangle); GN-FDT-M1[SK-FGG] (circle). (a) Glucose consumption (closed symbols), glycerol consumption (opened symbols), and (b) ethanol production (opened symbols). Fermentation was performed under semi-aerobic conditions in flasks with 20:200 liquid medium: flask volume at $30^{\circ} \mathrm{C}$ with shaking at $180 \mathrm{rpm}$. YP medium was supplemented with (w/v) $1.5 \%$ glucose and $6 \%$ glycerol. Data represent the average of three independent experiments that were running at the same time. Error bars represent the standard deviation of the mean.

Fig. 3. Module M1 for replacing $S c G U T 1$ via homologous recombination using multiplex CRISPR Cas 9. 


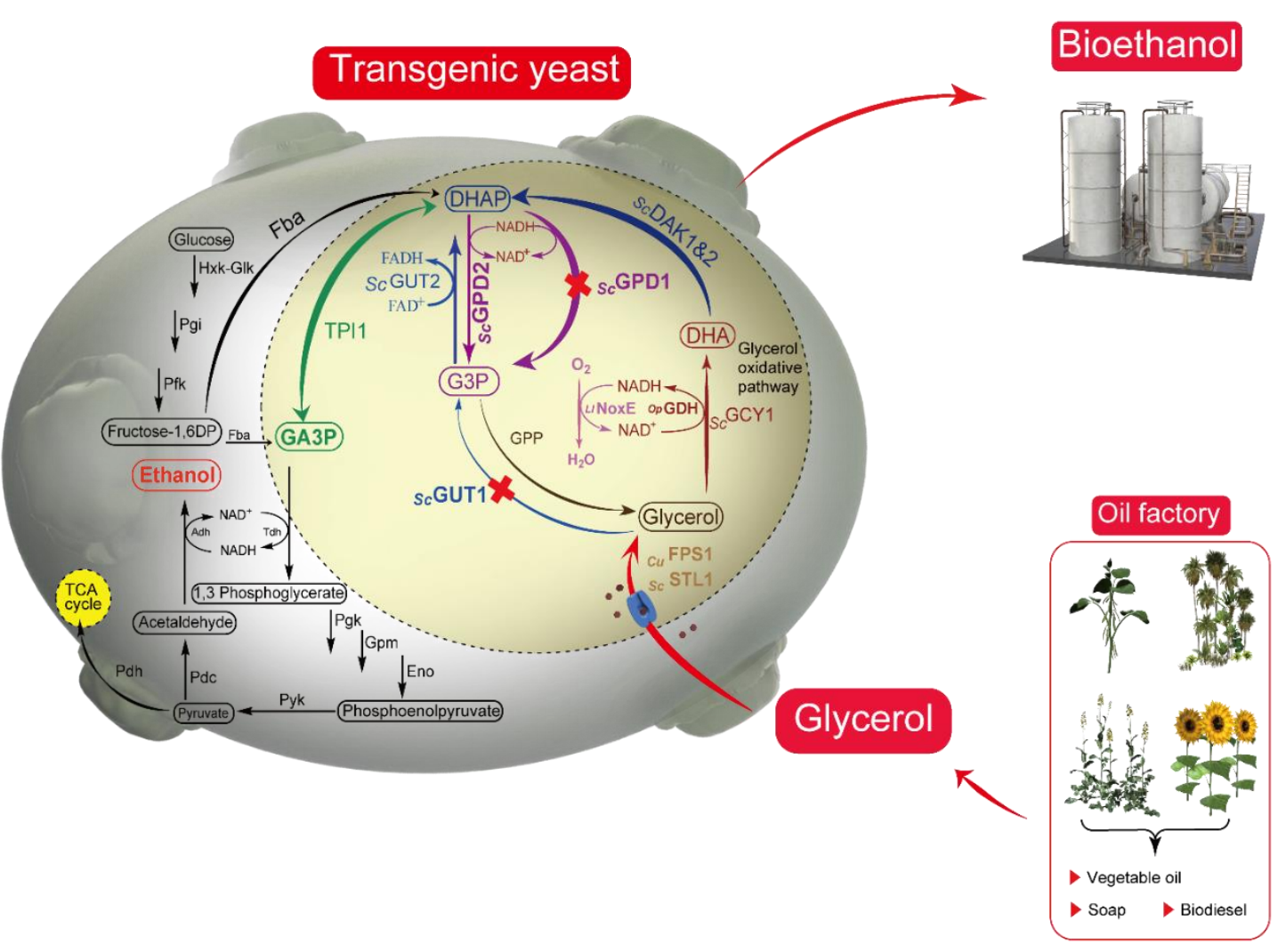

Fig.1. 


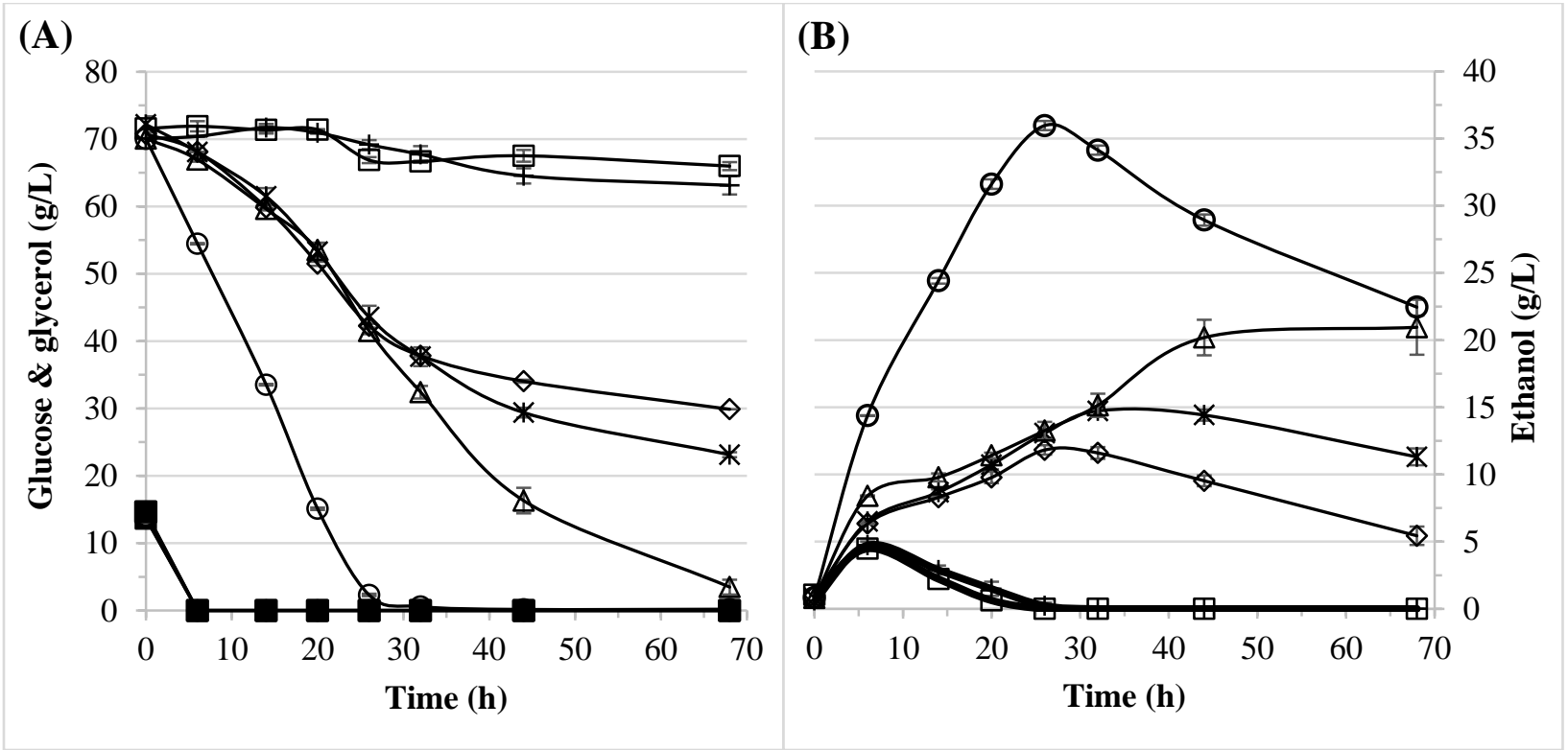

Fig. 2 


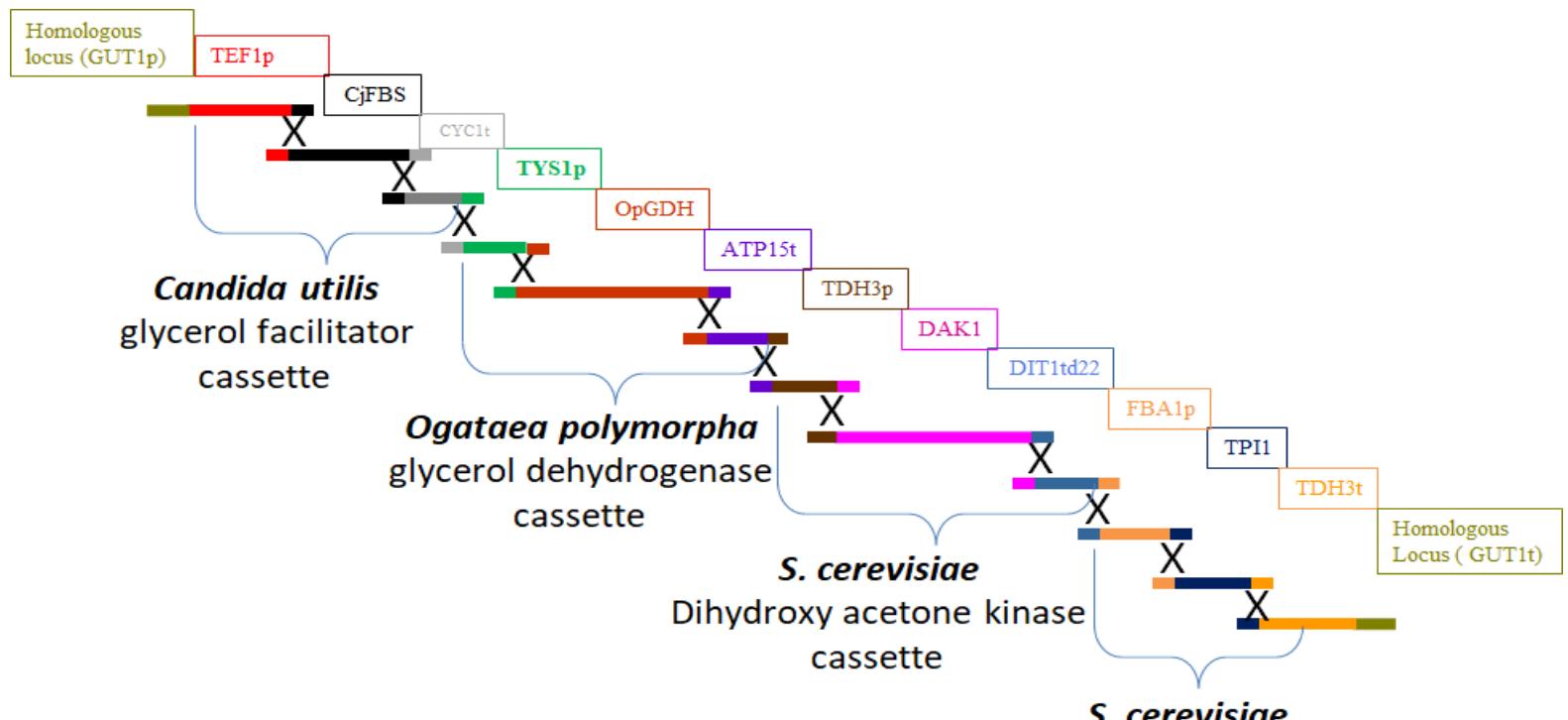

S. cerevisiae

Triose phosphate isomerase cassette

Fig. 3

641 


\begin{tabular}{|c|c|c|}
\hline S. cerevisiae strains & Relevant genotypes & Reference \\
\hline D452-2 & MATa leu2 his3 ura3 can1 & $(17)$ \\
\hline D452-2-URA3 & $D 452-2, U R A 3:: T D H 3$ promoter and $D I T 1_{d 22}$ terminator & This study \\
\hline GDH & $D 452-2, U R A 3: \because T D H 3-O p G D H-D I T 1_{d 22}$ & This study \\
\hline GPD1/NoxE (NOXE) & D452-2, $\triangle G P D 1: \because$ TDH3-LINoxE-DIT1 $1_{d 22}$ & this study \\
\hline GDH-NOXE (GN) & D452-2, URA3:: TDH3-OpGDH-DIT1 $1_{d 22} ; \Delta G P D 1:: T D H 3-L I N o x E-D I T 1_{d 22}$ & This study \\
\hline D452-2-URA3-AUR1-C & $D 452-2, U R A 3: \because T D H 3$ promoter and $D I T 1_{d 22}$ terminator:: AUR1-C & This study \\
\hline GN-FDT & 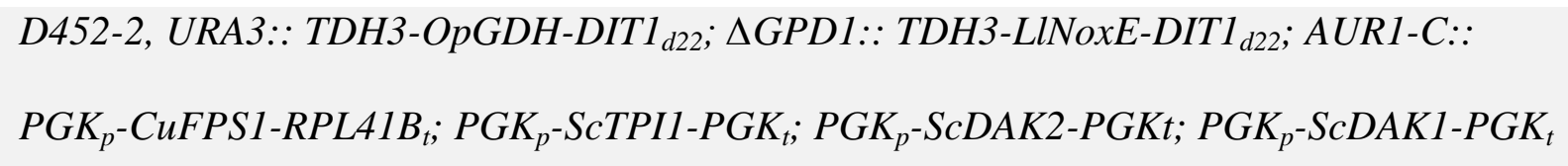 & This study \\
\hline GN-FDT-M1 (SK-FGG) & 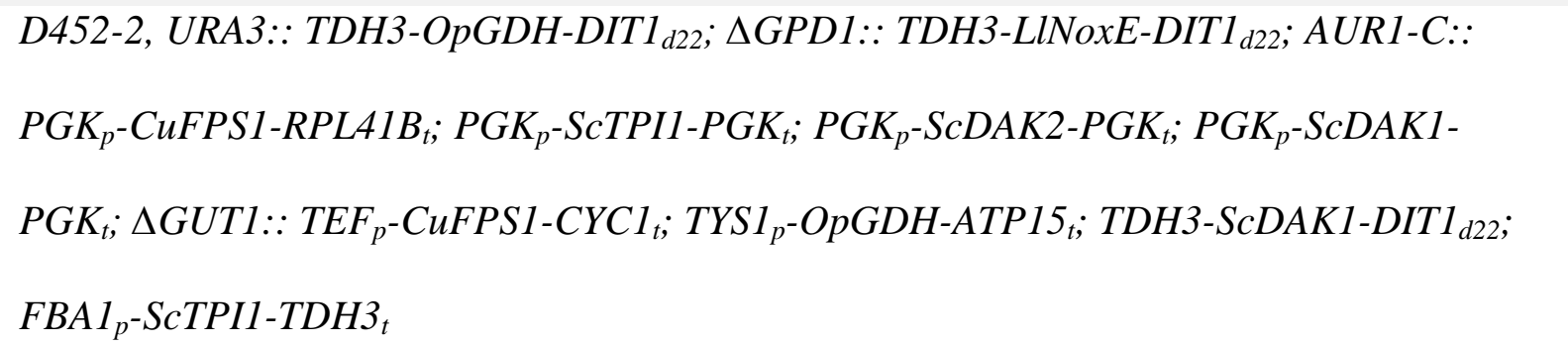 & This study \\
\hline
\end{tabular}


Table 2. Specific activities of glycerol dehydrogenase $(G D H)$, dihydroxyacetone kinase $(D A K)$, and triosephosphate isomerase (TPII), and NADH/NAD ${ }^{+}$ratio with their intracellular concentrations in the recombinant strains used in this study.

\begin{tabular}{|c|c|c|c|c|c|c|}
\hline \multirow{2}{*}{$\begin{array}{l}\text { Relevant } \\
\text { Strain }\end{array}$} & \multicolumn{3}{|c|}{ extracted proteins } & \multicolumn{2}{|c|}{ concentrations } & \multirow{2}{*}{$\begin{array}{l}\text { NADH/ NAD } \\
\text { ratio }\end{array}$} \\
\hline & $\begin{array}{l}\text { GDH } \\
\text { (mmole) }\end{array}$ & $\begin{array}{l}\text { DAKs } \\
\text { ( } \mu \text { mole) }\end{array}$ & $\begin{array}{l}\text { TPI1 } \\
\text { (mmole) }\end{array}$ & $\begin{array}{l}\text { NADH } \\
(\mu \mathrm{M})\end{array}$ & $\begin{array}{l}\mathrm{NAD}^{+} \\
(\mu \mathrm{M})\end{array}$ & \\
\hline WT-URA3 & $-0.6 \pm 0.1^{*}$ & $3.9 \pm 0.2$ & $15.3 \pm 0.2$ & $0.17 \pm 0.004$ & $0.36 \pm 0.01$ & $0.47 \pm 0.01$ \\
\hline GDH & $3.5 \pm 0.2$ & NMa & $12.6 \pm 0.9$ & $0.26 \pm 0.01$ & $0.38 \pm 0.02$ & $0.68 \pm 0.02$ \\
\hline NOXE & $-0.7 \pm 0.1^{*}$ & NMa & $13.8 \pm 0.4$ & $0.04 \pm 0.01$ & $0.36 \pm 0.04$ & $0.12 \pm 0.01$ \\
\hline GN & $5.3 \pm 0.2$ & NMa & $5.4 \pm 0.03$ & $0.34 \pm 0.02$ & $0.35 \pm 0.01$ & $0.99 \pm 0.02$ \\
\hline GN-FDT & $5.8 \pm 0.3$ & $7.2 \pm 0.2$ & $5.7 \pm 0.2$ & $0.17 \pm 0.01$ & $0.52 \pm 0.01$ & $0.33 \pm 0.02$ \\
\hline SK-FGG & $5.9 \pm 0.2$ & $18.3 \pm 0.3$ & $18 \pm 0.6$ & $0.11 \pm 0.01$ & $0.63 \pm 0.01$ & $0.18 \pm 0.01$ \\
\hline
\end{tabular}

* Absorption at $340 \mathrm{~nm}$ decreased over time, which indicates lack of activity of native glycerol dehydrogenase. Error values represent standard deviation of the mean $(n=2)$. $\propto$ indicates not measured. 

glucose in fed-batch culture.

Fermentation conditions and products values

\begin{tabular}{|c|c|c|c|c|}
\hline Parameter & One fed-batch & One fed-batch & Two fed-batch & Two fed-batch \\
\hline Fermentation time $(\mathrm{h})$ & $40 \pm 0.30$ & $40 \pm 0.30$ & $96 \pm 0.30$ & $96 \pm 0.30$ \\
\hline Total consumed glycerol (g/L) & $82.5 \pm 1.63$ & $75.77 \pm 1.4$ & $141.88 \pm 2.7$ & $141.7 \pm 5$ \\
\hline Initial glycerol concentration (g/L) & $111 \pm 1$ & $108.15 \pm 1$ & $108.17 \pm 1$ & $82.84 \pm 1$ \\
\hline Glycerol fed-batch concentration (g/L) & NA & NA & $94 \pm 1$ & $99 \pm 2.5$ \\
\hline Total consumed glucose (g/L) & NA & $22.5 \pm 1.2$ & $22.2 \pm 0.67$ & $44.7 \pm 1$ \\
\hline Rate of consumption $(\mathrm{g} \cdot \mathrm{L} \cdot \mathrm{h})$ & $2.1 \pm 0.2$ & $2.4 \pm 0.1$ & $1.7 \pm 0.1$ & $1.9 \pm 0.1$ \\
\hline Ethanol yield (g/L) & $40.4 \pm 0.1$ & $48.2 \pm 1.2$ & $79.7 \pm 1.1$ & $86.5 \pm 2.5$ \\
\hline Rate of ethanol production (g.L.h) & $1.01 \pm 0.01$ & $1.2 \pm 0.02$ & $0.83 \pm 0.01$ & $0.9 \pm 0.02$ \\
\hline Efficiency of ethanol production $\left(\mathrm{g}^{\mathrm{e}} / \mathrm{g}^{\mathrm{s}}\right)$ & $0.49 \pm 0.01$ & $0.49 \pm 0.01$ & $0.48 \pm 0.01$ & $0.46 \pm 0.01$ \\
\hline Efficient/ theoretical $(\%)^{+}$ & 98 & 98 & 97.2 & 92.8 \\
\hline Acetic acid accumulation (g/L) & $1.14 \pm 0.02$ & $1.12 \pm 0.02$ & $1.67 \pm 0.1$ & $2.46+0.02$ \\
\hline Total conversion $\left(\mathrm{g}^{\mathrm{p}} / \mathrm{g}^{\mathrm{s}}\right)^{++}$ & $0.5 \pm 0.01$ & $0.5 \pm 0.01$ & $0.5 \pm 0.01$ & $0.48 \pm 0.01$ \\
\hline Final cell density $\left(\mathbf{O D}_{600}\right)$ & $10.6 \pm 0.2$ & $11.6 \pm 0.2$ & $11.6 \pm 0.3$ & $15.2 \pm 0.3$ \\
\hline
\end{tabular}

Oxygen availability in liquid medium: flask volume at $30^{\circ} \mathrm{C}$ with shaking at $200 \mathrm{rpm}$ (20:200).

$652\left(\mathrm{~g}^{\mathrm{e}} / \mathrm{g}^{\mathrm{s}}\right) *$, gram ethanol per gram of glycerol. $\quad\left(\mathrm{g}^{\mathrm{p}} / \mathrm{g}^{\mathrm{s}}\right)^{++}$; gram products per gram of substrate. 

different oxygen availabilities.

\begin{tabular}{|c|c|c|c|c|}
\hline \multirow{2}{*}{$\begin{array}{l}\text { Parameter name } \\
\text { Oxygen availability\# }\end{array}$} & \multicolumn{4}{|c|}{ Fermentation conditions and products values } \\
\hline & Strict & Micro-aerobic & Semi-aerobic & Aerobic \\
\hline Fermentation time (h) & $96 \pm 0.30$ & $60 \pm 0.30$ & $48 \pm 0.30$ & $36 \pm 0.30$ \\
\hline Total consumed glycerol (g/L) & $0.00 \pm 0.45$ & $37.17 \pm 2.7$ & $54.01 \pm 5$ & $46.4 \pm 1$ \\
\hline Rate of consumption $(g \cdot L \cdot h)$ & $0.0 \pm 0.0$ & $0.62 \pm 0.4$ & $1.12 \pm 0.1$ & $1.3 \pm 0.1$ \\
\hline Total ethanol produced (g/L) & $0.0 \pm 0.0$ & $15.7 \pm 1.9$ & $21 \pm 1.3$ & $18 \pm 0.5$ \\
\hline Rate of ethanol production (g.L.h) & $0.0 \pm 0.0$ & $0.25 \pm 0.04$ & $0.44 \pm 0.02$ & $0.5 \pm 0.01$ \\
\hline Efficiency of ethanol production $\left(\mathrm{g}^{\mathrm{e}} / \mathrm{g}^{\mathrm{s}}\right)$ & $0.0 \pm 0.0$ & $0.42 \pm 0.05$ & $0.39 \pm 0.01$ & $0.39 \pm 0.01$ \\
\hline Efficient/ theoretical (\%) & 0 & 84 & 78 & 78 \\
\hline Acetic acid accumulation (g/L) & $0.0 \pm 0.0$ & $0.87 \pm 0.21$ & $2.9 \pm 0.2$ & $3 \pm 0.1$ \\
\hline Total conversions $\left(g^{p} / g^{s}\right)$ & $0.0 \pm 0.0$ & $0.45 \pm 0.1$ & $0.44 \pm 0.1$ & $0.45 \pm 0.1$ \\
\hline
\end{tabular}




\begin{tabular}{|c|c|c|}
\hline Plasmids & Relevant genotypes & Reference \\
\hline pPGK-URA3 & $U R A 3 ; P G K$ promoter and terminator & $(44)$ \\
\hline TDH3-DIT1 $1_{\mathrm{d} 22}$-URA3 & $U R A 3, T D H 3$ promoter and mutated $D I T 1_{d 22}$ terminator & This study \\
\hline TDH3-GDH-DIT1 $1_{\mathrm{d} 22}$-URA3 & $U R A 3$; expresses $O p G D H$ & This study \\
\hline TDH3-NoxE-DIT1 $1_{\mathrm{d} 22}$-URA3 & $U R A 3$; expresses LINoxE & This study \\
\hline pPGK-DAK1-URA3 & $U R A 3$; expresses $S c D A K 1$ & This study \\
\hline pPGK-DAK2-URA3 & $U R A 3$; expresses $S c D A K 2$ & This study \\
\hline pPGK-TPI1-URA3 & URA3; expresses ScTPII & This study \\
\hline pPGK-TPI1-DAK2-URA3 & URA3; expresses ScTPII, ScDAK2 & This study \\
\hline pPGK-TPI1-DAK2-DAK1-URA3 & $U R A 3$; expresses $S c T P I 1, S c D A K 2, S c D A K 1$ & This study \\
\hline pAUR101 & $A U R I-c$ & Takara Bio \\
\hline pAUR101-PGK-RPL41B & $A U R 1-C, P G K$ promoter-RPLA1B terminator & This study \\
\hline pAUR101-FPS1 & $A U R 1-C$; expresses $C u F P S 1$ & This study \\
\hline pAUR101-FPS1-TPI1-DAK2- & AUR1-C; expresses CuFPS1, ScTPI1, ScDAK2, ScDAK1 & This study \\
\hline
\end{tabular}


pAUR101- M1*

Multiplex pCAS (Addgene \#60847)

Multiplex pCAS/GPD1-1

Multiplex pCAS/GPD1-2

Multiplex pCAS/GUT1
AUR1-C; expresses CuFPS1, OpGDH, ScDAK1, ScTPI1

Multiplex expresses Cas9 and HDV ribozyme-sgRNA

Multiplex expresses Cas9 and gRNA to base No. 135 of ScGPD1

Multiplex expresses Cas9 and gRNA to base No. 1045 of ScGPD1

Multiplex expresses Cas9 and gRNA to base No. 616 of ScGUT1
This study

This study

This study

This study

*M1: TEFp-CuFPS1-CYC1t; TYS1p-OpGDH-ATP15t; TDH3p-ScDAK1-d22-DIT1t; FBA1p-ScTPI1-TDH3t 
